\title{
The Moderating Capacity of Racial Identity Between Perceived Discrimination and Psychological Well-Being Over Time Among African American Youth
}

\author{
Eleanor K. Seaton, Enrique W. Neblett, \\ Rachel D. Upton, and \\ Wizdom Powell Hammond \\ University of North Carolina at Chapel Hill
}

\author{
Robert M. Sellers \\ University of Michigan
}

\begin{abstract}
This study examined the influence of racial identity in the longitudinal relation between perceptions of racial discrimination and psychological well-being for approximately 560 African American youth. Latent curve modeling (LCM) and parallel process multiple-indicator LCMs with latent moderators were used to assess whether perceptions of racial discrimination predicted the intercept (initial levels) and the slope (rate of change) of psychological well-being over time, and whether racial identity moderates these relations. The results indicated that African American adolescents who reported higher psychological responses to discrimination frequency levels at the first time point had lower initial levels of well-being. Regressing the slope factor for psychological well-being on the frequency of discrimination also revealed a nonsignificant result for subsequent well-being levels.
\end{abstract}

The phenomenological variant of ecological systems theory (PVEST) model is the framework for examining racial identity as a moderator for the longitudinal relation between perceptions of racial discrimination and psychological well-being among African American youth. PVEST incorporates ecological systems theory with identity development in describing normative processes for minority youth (Spencer, Fegley, \& Harplani, 2003). Specifically, PVEST argues that racial discrimination is a risk factor, which increases the net vulnerability for youth of color and may result in adverse consequences if youth do not develop appropriate coping strategies and support skills (Spencer, 2006). Additional conceptualizations suggest emergent identities arise out of coping with stressors like racial discrimination as minority youth appraise their role in specific situations (Spencer, 2005). The identities

This research was supported by grants from the National Institute of Mental Health (NIMH 5 R01 MH061967-03), the National Center on Minority Health and Health Disparities, and the National Science Foundation (BCS-9986101). We thank the members of the African American Family Project for their help and support with the project.

Correspondence concerning this article should be addressed to Eleanor K. Seaton, Department of Psychology, The University of North Carolina at Chapel Hill, Campus Box 3270, Davie Hall, Chapel Hill, NC 27599-3270. Electronic mail may be sent to eseaton@unc.edu. that minority youth develop provide the foundation for productive or adverse developmental outcomes throughout the life span (Spencer, 2006; Spencer et al., 2003). Therefore, it is important to know the role that identity plays in relation to developmental outcomes in the context of a chronic and pervasive stressor such as racial discrimination among minority youth (Swanson et al., 2003). Additionally, it may be important to study these processes during the developmental period when identity issues are heightened (Erikson, 1968) and developmental changes in racial identity are evidenced among minority youth (French, Seidman, Allen, \& Aber, 2006; Pahl \& Way, 2006; Seaton, Scottham, \& Sellers, 2006). In the present study, we apply this model to examine the role of racial identity in the longitudinal relation between perceptions of racial discrimination and psychological wellbeing. Specifically, the present study explored whether perceptions of racial discrimination predicted initial levels of psychological well-being and changes in the rate of psychological well-being over time. We also examined whether these relations were moderated by racial identity over time among African American youth.

(C) 2011 The Authors

Child Development (C) 2011 Society for Research in Child Development, Inc. All rights reserved. 0009-3920/2011/8206-0012

DOI: 10.1111/j.1467-8624.2011.01651.x 


\section{Racial Discrimination}

Racial discrimination is defined as dominant group members' actions, which are systematic, that result in differential and negative effects on subordinate racial/ethnic groups (Williams, Neighbors, \& Jackson, 2003). PVEST suggests that racial discrimination increases the likelihood of negative developmental outcomes because it increases the net vulnerability for youth of color who lack appropriate coping strategies for discriminatory treatment (Spencer, 2006). Among African American youth, perceptions of racial discrimination have been linked to a diversity of outcomes. For example, perceptions of racial discrimination have been negatively linked to achievement motivation, grade point average, school engagement, and math skills (Burchinal, Roberts, Zeisel, \& Rowley, 2008; Fisher, Wallace, \& Fenton, 2000; Powell \& Arriola, 2003; Smalls, White, Chavous, \& Sellers, 2007). Perceived discrimination has also been linked to lower life satisfaction levels, decreased self-esteem, increased depressive symptoms, increased anxiety, increased anger, and increased problem behaviors (GaylordHarden \& Cunningham, 2009; Prelow, Danoff-Burg, Swenson, \& Pulgiano, 2004; Seaton, Caldwell, Sellers, \& Jackson, 2008; Wong, Eccles, \& Sameroff, 2003). Finally, perceived racial discrimination has been positively linked to an increased likelihood of smoking and alcohol consumption among African American youth (Guthrie, Young, Williams, Boyd, \& Kintner, 2002; Terrell, Miller, Foster, \& Watkins, 2006). Whereas it has been suggested that diminished psychological health or well-being might lead to increased perceptions of discrimination (Phinney, Madden, \& Santos, 1998), there is a growing body of research that has tested both predictions and found that perceptions of discrimination are linked to diminished outcomes. For example, perceptions of racial discrimination were linked to increased depressive symptoms, subsequent drug use, increased conduct problems, increased perceived stress, decreased self-esteem, and decreased levels of well-being among African American youth (Brody et al., 2006; Gibbons, Gerrard, Cleveland, Wills, \& Brody, 2004; Gibbons et al., 2007; Greene, Way, \& Pahl, 2006; Neblett et al., 2008). Also, daily perceptions of racial discrimination from peers and teachers predicted declining grade point averages and academic self-concepts among African American adolescents (Chavous, Rivas-Drake, Smalls, Griffin, \& Cogburn, 2008; Eccles, Wong, \& Peck, 2006). Thus, burgeoning research suggests that perceptions of racial discrimination are linked to diminished psychological well-being and increased risky behaviors among African American youth.

Yet, the bulk of empirical research has assessed perceptions of discriminatory treatment among youth of color. In their study of emotional reactions to daily stress, Bolger and Zuckerman (1995) proposed two mechanisms by which stress may affect mental health, including individual differences in exposure and reactivity to stressful life events. The differential-reactivity hypothesis suggests that individuals with lower status are vulnerable to healthrelated stressors because they demonstrate a heightened reactive response to stress (Bolger \& Zuckerman, 1995). The bulk of research examining racial discrimination among adolescent populations has not examined the response to the experience, only the frequency of whether it occurred. Among a sample of African American adults, the common emotional responses to perceptions of racial discrimination included feeling angry, feeling hurt, and feeling frustrated, whereas some of the behavioral responses included speaking up and prayer (Barksdale, Farrug, \& Harkness, 2009). The results from a study of African American adults indicated that perceptions of racial discrimination did not increase reactivity (Ong, Fuller-Rowell, \& Burrow, 2009). In the current study, we distinguish the frequency of a racially discriminatory event from the response to the event among African American youth.

\section{Racial Identity as a Moderator for Racial Discrimination}

Racial identity is defined as the significance and meaning that individuals ascribe to being a member of their racial group (Sellers, Smith, Shelton, Rowley, \& Chavous, 1998). PVEST suggests that the identities that minority youth form provide the bedrock for productive or adverse developmental outcomes (Spencer, 2006). The role of racial identity becomes especially important in the context of a risk factor such as racial discrimination among minority youth (Swanson et al., 2003), and racial identity has been examined as a protective factor for perceptions of racial discrimination among minority youth. Previous empirical research has examined various dimensions of the multidimensional model of racial identity (MMRI) as moderators for perceptions of racial discrimination. The MMRI articulates individual differences in the meaning and significance that African Americans ascribe to racial identity content (Sellers et al., 1998). The MMRI comprises three related dimensions: centrality, regard, and ideology. Racial 
centrality refers to the extent to which an individual normatively defines her racial group membership or the significance that individuals place on race (Sellers et al., 1998). The second dimension, racial regard, refers to individuals' affective attitudes toward African Americans and is divided into two components: private regard and public regard (Sellers et al., 1998). Private regard refers to the extent to which an individual feels positively or negatively about being a member of the African American community. Public regard refers to the extent to which an individual feels that the broader society views the African American community positively or negatively. The third dimension, racial ideology, refers to one's philosophy regarding the ways that African Americans should behave and consists of four components: nationalist, minority, assimilationist, and humanist (Sellers et al., 1998). The nationalist ideology emphasizes the uniqueness of being African American, support of African American organizations, and preference for African American social environments. The minority ideology emphasizes the similarities between African Americans' experiences and those of other oppressed minority groups. An assimilationist ideology emphasizes the similarities between African American and mainstream American society, and the humanist ideology emphasizes the similarities among all people regardless of race or ethnicity.

Previous empirical research using racial identity dimensions suggests that the relation between perceptions of racial discrimination and depressive symptoms was nonsignificant for adolescents who held low public regard levels (Sellers, Linder, Martin, \& Lewis, 2006). Racial ideology has also been shown to moderate perceived racial discrimination such that African American youth with assimiliationist views showed lower academic identification when reporting racially discriminatory experiences (Smalls et al., 2007). Additional empirical research using longitudinal designs have indicated that racial identity buffers perceptions of racial discrimination among African American youth. Specifically, African American adolescents who perceived high levels of racial discrimination but had a strong connection to their racial group (high private regard levels) were performing as well as youth who perceived little to no racial discrimination (Eccles et al., 2006). Similarly, perceptions of peer discrimination in 8th grade were linked to school importance in 11th grade for African American boys and girls who had low racial centrality levels (Chavous et al., 2008). Yet, the relation between perceptions of classroom dis- crimination in 8th grade and grade point average in 11th grade was attenuated for girls and boys who had high racial centrality levels (Chavous et al., 2008). Previous research has been consistent in that several racial identity constructs have been shown to moderate perceptions of racial discrimination among African American adolescents.

\section{The Present Study}

The current study will add to existing literature through the combination of specific statistical techniques-parallel process multiple-indicator latent curve models (LCMs) with latent variable interactions. The parallel process LCM or multivariate LCM contains two or more sets of intercepts and slopes, one set for each repeated measures variable, and it allows directional paths among latent factors (e.g., latent intercepts and latent slopes) to be specified within a given model (MacCallum, Zhang, Preacher, \& Rucker, 2002). The parallel process model is particularly useful when dealing with time-varying covariates (i.e., discrimination bothered or frequency of discrimination; see Bollen \& Curran, 2006). The multiple-indicator LCM or second-order latent growth model also provides a number of statistical benefits, including tests for measurement invariance for longitudinal data with multiple items observed repeatedly over time (Bollen \& Curran, 2006; Hancock \& Kuo, 2001; Sayer \& Cumsille, 2001). Finally, this study uses latent variable moderation (Bollen, 1989; Schumacker \& Marcoulides, 1998), which allows one to test for interactions between two or more latent, unobserved factors.

The present study will also add to existing literature by distinguishing the frequency of racial discrimination from adolescents' reaction to racially discriminatory events. Previous research has primarily focused on the frequency of the event (Brody et al., 2006; Gibbons et al., 2007; Greene et al., 2006), without examining youth's responses to discriminatory treatment whereas prior research indicates emotional and behavioral responses to discriminatory treatment among African American adults (Barksdale et al., 2009). Furthermore, the long-term effect of perceived racial discrimination on psychological well-being might vary depending on whether the frequency of discrimination or the degree to which one is bothered is being assessed, and the present study affords the opportunity to examine these distinct relations.

The first research question examines the longitudinal relation between racial discrimination (i.e., 
discrimination bother or discrimination frequency levels) and psychological well-being. Consistent with prior cross-sectional and longitudinal research (Brody et al., 2006; Greene et al., 2006; Neblett et al., 2008; Seaton et al., 2008; Wong et al., 2003), we expected that the frequency of racial discrimination will be negatively associated with the initial assessment of psychological well-being at Time 1 (i.e., latent intercept) and the rate of change in psychological well-being over time (i.e., latent slope). We also anticipated that the degree to which one is bothered by discrimination will be negatively associated with the initial assessment of psychological well-being at Time 1 (i.e., intercept factor) and the rate of change in psychological well-being (i.e., slope factor). The second research question examines whether the relation between psychological well-being and racial discrimination (i.e., discrimination bother or discrimination frequency levels) is moderated by racial identity (i.e., racial centrality, private regard, public regard, nationalist ideology, minority ideology, assimilationist ideology, and humanist ideology) over time. We anticipated that the frequency of discrimination and being bothered by discrimination will be differentially linked to psychological well-being depending on the specific racial identity dimensions. Based on prior empirical research, we expected that low public regard levels (Sellers et al., 2006), high private regard levels (Eccles et al., 2006), and high racial centrality levels (Chavous et al., 2008) would moderate perceptions of racial discrimination frequency and being bothered by discrimination.

\section{Method}

\section{Participants}

These data are drawn from a 3-year longitudinal study of racial identity development, racial socialization, and psychological adjustment among African American adolescents residing in the Midwest. Ten schools (six middle and four high schools) located in a Midwestern public school district were the recruitment sites for the study. White students (57\%) comprised the majority of the school district, and African American students $(15.1 \%)$ were the second largest group of students in the school district. Five hundred and seventytwo participants were recruited at Time 1 and a total of 260 students were assessed in the 3rd and final year of the study. All available participants from Time 1 through Time 3 were retained in the final analyses. Participant ages ranged from 12 to
$17(M=13.82, S D=1.11)$ at Time 1,13 to 17 $(M=14.81, S D=1.11)$ at Time 2 , and 14 to 18 $(M=15.78, S D=1.20)$ at Time 3 . The average age for Time 1 was $13.74(S D=1.28)$. The average age for Time 2 was $14.74(S D=1.21)$ and the mean age at Time 3 was $15.78(S D=1.20)$. Across all three time points, females comprised the majority of the sample. For example, the sample was $41 \%$ male and $59 \%$ female at Time 1 , and $39 \%$ male and $61 \%$ female at Time 3. The median family income was reported to be between $\$ 40,000$ and $\$ 49,999$ at Time 3. The mode education level for parents or caregivers was some college across all three time points. Preliminary analyses revealed no significant differences with respect to demographic factors or key study measures between participants who participated at Time 1 only and those participating at all three time points.

\section{Procedure}

The specific procedures for the longitudinal study have been described elsewhere (see Seaton et al., 2006; Sellers et al., 2006). Public school administrators assisted with recruiting participants and their primary caregivers who were contacted via telephone and mail. To be eligible for the study, participants had to be students of African descent who were attending one of the school sites enrolled in the study. Primary caregivers indicated their agreement to participate in the study by signing and returning a consent form before the scheduled survey administration. Adolescent participants signed an assent form at the time of data collection. Each survey administration was conducted in groups and led by an African American research assistant. The surveys were administered on site and lasted between 45 and $75 \mathrm{~min}$. Adolescents received gift cards in the amount of $\$ 30$ (Time 1), $\$ 40$ (Time 2), and \$50 (Time 3) in exchange for their participation in the study.

\section{Measures}

Racial identity. Racial identity was assessed with the Multidimensional Inventory of Black IdentityTeen (MIBI-T; Scottham, Sellers, \& Nguyên, 2008), which was adapted for use among youth from the original MIBI model. Confirmatory factor analysis (CFA) found the original MIBI model to be an adequate fit for the MIBI-T, which since has also been used successfully in research with African American adolescents (see Sellers et al., 2006). The MIBI$\mathrm{T}$ has seven subscales that assess three dimensions 
of racial identity: centrality, regard, and ideology. Responses for items used to measure centrality, regard (private regard and public regard), and ideology (nationalist, minority, assimilationist, and humanist) ranged from 1 (strongly disagree) to 5 (strongly agree). Racial centrality was examined using two items, measured at each of the three time points: "I feel close to other Black people" and "I have a strong sense of belonging to other Black people." Private regard was measured using two items assessed at each time point: "I am happy that I am Black" and "I am proud to be Black." Similarly, public regard was measured using two items: "Most people think that Blacks are as smart as people from other races" and "People think Blacks are as good as people from other races." Nationalist ideology was measured using two separate items, measured at each of the three time points: "Whenever possible, Blacks should buy from Black businesses" and "Blacks should support Black entertainment by going to Black movies and TV shows." Minority ideology was examined using two items measured at each of the three waves of data: "Blacks should spend less time focusing on how we are different from other minority groups and more time focusing on how we are similar" and "Racism that Blacks have experienced is similar to that of other minority groups." Assimilationist ideology was measured using two separate items: "It is important that Blacks go to White schools" and "I think it is important for Blacks not to act Black around White people." Finally, humanist ideology was measured using two items across each of the three time points: "Being an individual is more important than identifying yourself as Black" and "Blacks should think of themselves as individuals, not as Blacks."

Perceptions of discrimination frequency and bother. The frequency of and bother associated with discriminatory experiences was assessed with the 18-item Daily Life Experiences (DLE) subscale of the Racism and Life Experiences Scale (RaLes; Seaton, Yip, \& Sellers, 2009). The RaLes was designed to assess collective, individual, and vicarious racism experiences of three types: life event/episodic stress, daily hassles, and chronic/ contextual stress (Harrell, 1994). The DLE is a selfreport measure that assesses daily hassles or the frequency of "microaggressions" because of race in the past year. Participants were presented with a list of experiences and asked to indicate how often it occurred to them in the past year "because you were Black" $(0=$ never, $1=$ once, $2=a$ few times, 3 =about once a month, $4=a$ few times a month,
5 = once $a$ week or more). Sample items included: "Having your ideas ignored" and "Not being taken seriously" (T1: $\alpha=.91 ; \mathrm{T} 2: \alpha=.91 ; \mathrm{T} 3: \alpha=.91$ ). In previous psychometric analyses, this subscale demonstrated adequate internal consistency, with assessments of construct validity indicating that daily life experiences were negatively correlated with social desirability and cultural mistrust (Harrell, 1994). Evidence of criterion-related validity was also demonstrated and revealed a positive relation between daily life experiences and perceived stress, psychological symptoms and traumarelated symptoms (Harrell, 1994). Participants were also asked to indicate how much they were bothered by each of these discriminatory experiences $(0=$ has never happened, $1=$ bothers me a little, $2=$ bothers me somewhat, $3=$ bothers me a lot, $4=$ bothers me extremely; T1: $\alpha=.92 ; \mathrm{T} 2: \alpha=.93 ; \mathrm{T} 3: \alpha=.91$ ). A mean score for the discrimination frequency and bother subscales was computed for each of the three time points such that higher scores indicate more frequent exposure to and bother associated with discrimination.

Psychological well-being. Psychological well-being was assessed with a 24-item shortened version of the Psychological Well-Being Scale (Ryff, 1989). This measure assesses psychological well-being along several dimensions: self-acceptance, positive relationships with others, autonomy, environmental mastery, purpose in life, and personal growth. One latent factor was identified in previous research studies utilizing the long version (48 items) of this measure (Ryff, 1989; Ryff \& Keyes, 1995). A sample item includes: "In general, I feel I am in charge of my life." Possible responses to the items on this scale range from 1 (strongly disagree) to 5 (strongly agree). A mean score was computed across each of the time points, such that higher scores indicate higher levels of psychological well-being (T1: $\alpha=.83$; T2: $\alpha=.80$; T3: $\alpha=.78$.

\section{Results}

\section{Descriptive Analysis}

Bivariate correlations for psychological wellbeing, discrimination bothered, frequency of discrimination, and items related to racial identity (i.e., racial centrality, private regard, public regard, nationalist ideology, assimilationist ideology, humanist ideology, and minority ideology) for Time 1 through Time 3 are displayed in Table 1. Means 


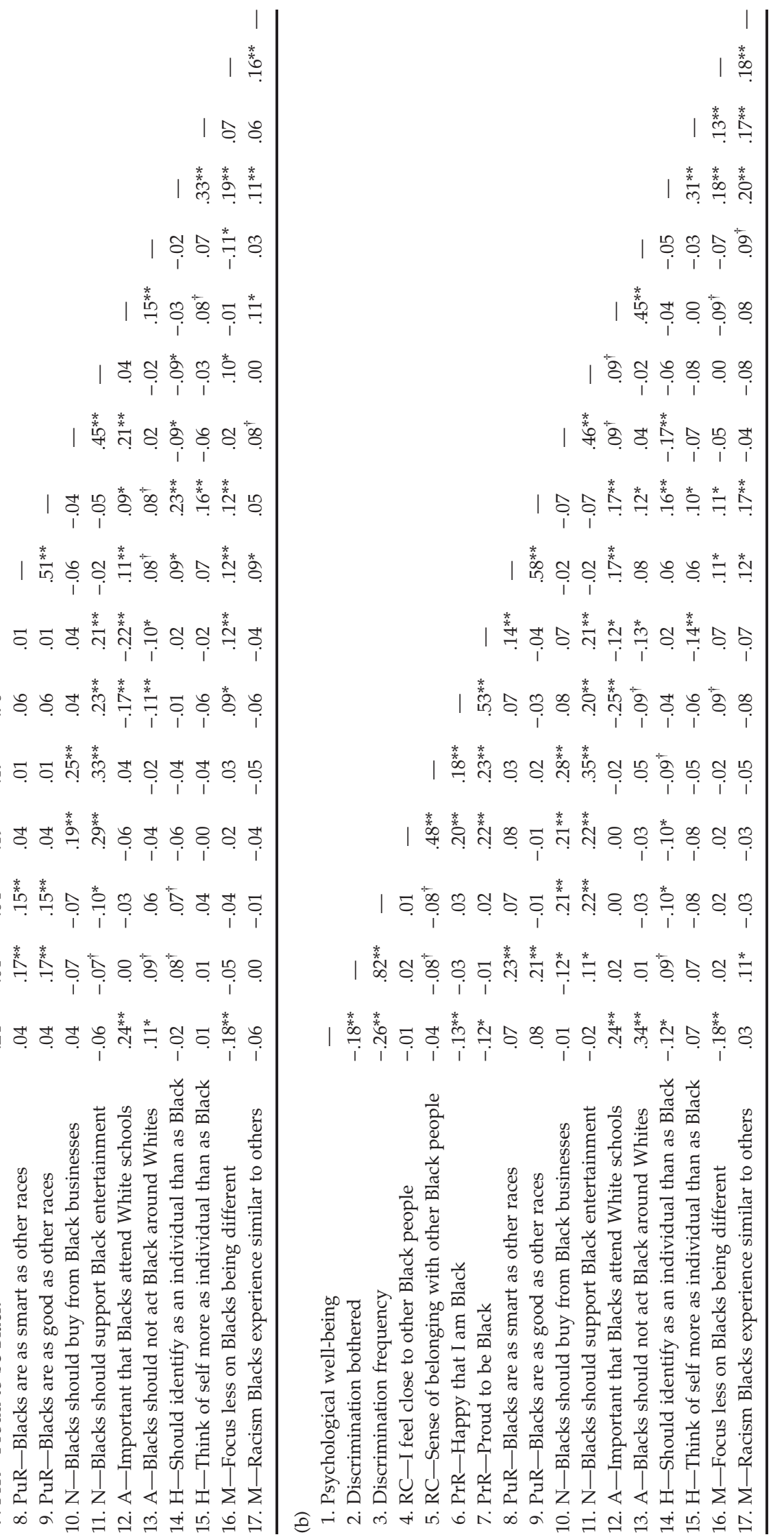




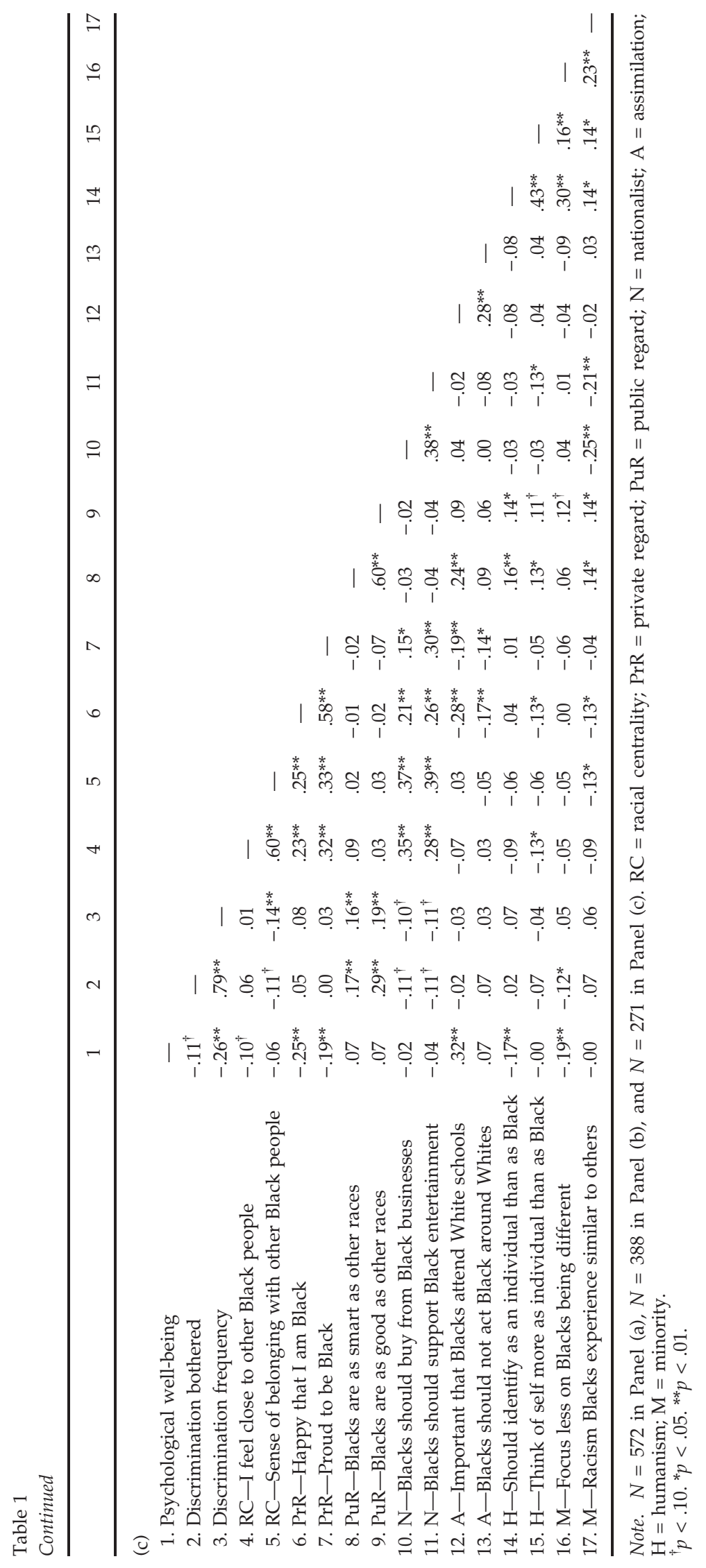


Table 2

Means and Standard Deviations of Study Variables at Time 1, Time 2, and Time 3

\begin{tabular}{|c|c|c|c|c|c|c|}
\hline \multirow[b]{2}{*}{ Study variables } & \multicolumn{2}{|c|}{ Time 1} & \multicolumn{2}{|c|}{ Time 2} & \multicolumn{2}{|c|}{ Time 3} \\
\hline & $M$ & $S D$ & $M$ & $S D$ & $M$ & $S D$ \\
\hline Psychological well-being & 3.63 & 0.55 & 3.58 & 0.53 & 3.68 & 0.54 \\
\hline Discrimination bothered & 1.77 & 1.17 & 1.95 & 1.28 & 2.02 & 1.23 \\
\hline Discrimination frequency & 1.60 & 1.07 & 1.52 & 0.99 & 1.59 & 0.96 \\
\hline \multicolumn{7}{|l|}{ Racial centrality } \\
\hline I feel close to other Black people & 1.80 & 0.94 & 1.86 & 1.03 & 1.82 & 0.94 \\
\hline Sense of belonging with other Black people & 2.43 & 1.11 & 2.36 & 1.09 & 2.35 & 1.06 \\
\hline \multicolumn{7}{|l|}{ Private regard } \\
\hline Happy that I am Black & 1.30 & 0.68 & 1.40 & 0.83 & 1.35 & 0.72 \\
\hline Proud to be Black & 1.28 & 0.69 & 1.27 & 0.70 & 1.23 & 0.58 \\
\hline \multicolumn{7}{|l|}{ Public regard } \\
\hline Blacks are as smart as other races & 2.83 & 1.24 & 2.88 & 1.25 & 3.09 & 1.22 \\
\hline Blacks are as good as other races & 2.72 & 1.23 & 2.85 & 1.21 & 2.93 & 1.11 \\
\hline \multicolumn{7}{|l|}{ Nationalist ideology } \\
\hline Blacks should buy from Black businesses & 2.99 & 1.26 & 2.77 & 1.19 & 2.53 & 1.17 \\
\hline Blacks should support Black entertainment & 2.57 & 1.18 & 2.47 & 1.11 & 2.28 & 1.01 \\
\hline \multicolumn{7}{|l|}{ Assimilationist ideology } \\
\hline Important that Blacks attend White schools & 1.75 & 0.95 & 1.75 & 0.91 & 1.81 & 0.90 \\
\hline Blacks should not act Black around Whites & 2.99 & 1.26 & 2.77 & 1.19 & 2.53 & 1.17 \\
\hline \multicolumn{7}{|l|}{ Humanist ideology } \\
\hline More important to identify as an individual than as Black & 2.16 & 1.14 & 2.10 & 1.05 & 1.98 & 1.04 \\
\hline Should think of self more as individual than as Black & 2.58 & 1.30 & 2.60 & 1.27 & 2.45 & 1.16 \\
\hline \multicolumn{7}{|l|}{ Minority ideology } \\
\hline Focus less on Blacks being different from others & 2.06 & 1.00 & 2.18 & 1.01 & 2.10 & 0.98 \\
\hline Racism Blacks experience similar to other minorities & 2.73 & 1.23 & 2.72 & 1.21 & 2.67 & 1.22 \\
\hline
\end{tabular}

and standard deviations of the study variables (i.e., psychological well-being, perceived discrimination, and racial identity) for each of the three waves of data are displayed in Table 2 .

\section{Data Analytic Approach}

The present study examines two research questions. The first question investigates whether perceptions of racial discrimination (i.e., discrimination bother or discrimination frequency levels) are linked to initial levels of psychological wellbeing measured at Time 1 (i.e., intercept factor), and the rate at which psychological well-being changes (i.e., slope factor) over time (Singer \& Willett, 2003). The second question investigates whether racial identity constructs, such as racial centrality, private regard, public regard, nationalist ideology, minority ideology, assimilationist ideology, and humanist ideology, moderate the relation between perceived discrimination (i.e., discrimination bother or discrimination frequency) and psychological well-being over time. Analyses were conducted to examine each of the two research questions using
Mplus Version 5 (Muthén \& Muthén, 1998-2007). Direct maximum likelihood was also utilized such that all participants with available data were included in the analyses (Bollen \& Curran, 2006).

Prior to examining multiple-indicator LCMs and parallel process multiple-indicator LCMs, we constructed a series of CFA models to test for measurement invariance (i.e., longitudinal measurement invariance) among each of the constructs relating to racial identity over time (Bollen, 1989; Bollen \& Curran, 2006; Meredith, 1993). Utilizing CFA models and chi-square difference tests, the ordering of invariance started with configural invariance (i.e., having the same structure of free and fixed parameters while imposing no equality constraints on the factor loadings and intercepts across the three waves of data), weak factorial invariance (i.e., factor loadings constrained to be equal across the three waves of data), and strong factorial invariance (i.e., factor loadings and intercepts of observed indicators constrained to equality across the three waves of data). Furthermore, measurement invariance was established for each of the models assessing the racial identity subscales using an alpha level of .01. 
The Longitudinal Relation Between Psychological Well-Being and Perceptions of Racial Discrimination

Before assessing the first research question, a series of nested, unconditional LCMs were examined for psychological well-being. The first LCM tested was an intercept-only model with unequal residual variances over time, the second model included a linear intercept and slope term with unequal residual variances, and the final model was similar to the second model with the inclusion of equal residual variances across the three time points. Based on the results of chi-square difference tests and an examination of the model fit statistics, an LCM with equal residual variances was found to provide the best overall fit, $\chi^{2}(3)=11.12, p<.05$, comparative fit index $(\mathrm{CFI})=.96$, root mean square error of approximation (RMSEA) $=.07$. The mean intercept of the trajectory for the unconditional LCM was estimated at $3.61(p<.05)$, and the mean slope trajectory was estimated at $.01(p>.05)$. The variance of the intercept factor was estimated at $.19(p<.01)$, and the variance of the slope factor was estimated at $.05(p<.01)$. Taken altogether, when attempting to establish the nature of the trajectories of the LCM for psychological well-being, a linear model appeared to fit the data.

A series of nested unconditional LCMs were also examined for racial discrimination (bother) and frequency of racial discrimination. For discrimination (bothered), the best fitting model was an unconditional LCM with an intercept and slope factor (with unequal residual variances), $\chi^{2}(1)=1.71, p>.05$, $\mathrm{CFI}=.99, \mathrm{RMSEA}=.04$. The mean intercept of the trajectory was estimated at $1.78(p<.05)$ and the mean slope trajectory was estimated at .13 $(p<.05)$. The variance of the intercept and slope factor were estimated at $.89(p<.01)$ and $.19(p<.05)$, respectively. Hence, when determining the nature of the trajectories of the LCM for discrimination bothered, a linear model was deemed adequate. Similarly, the best fitting LCM for frequency of discrimination included an intercept and slope factor with unequal residual variances, $\chi^{2}(1)=2.20, p>.05, \mathrm{CFI}=.99$, RMSEA $=.05$. When assessing the unconditional LCM for frequency of discrimination, the mean intercept of the trajectory was $1.58(p<.05)$ and the mean slope trajectory was estimated at -.02 $(p>.05)$. The variance of the intercept factor was estimated at $1.58(p<.05)$, whereas the variance of the slope factor was estimated at $.05(p>.05)$.

The variance of the slope factor for frequency of discrimination was statistically nonsignificant (using an alpha level of .05) and individuals did not exhibit significant variation in their rates of change in the frequency of discrimination over time. Thus, the relation between psychological well-being and frequency of discrimination was examined in Model 1, whereby the intercept and slope factor for psychological well-being were regressed on the observed measure for frequency of discrimination at Time 1 (see Figure 1 for a pictorial display of Model 1). In Model 1, frequency of discrimination at Time 1 was mean-centered prior to performing the final analyses. For Model 2, the longitudinal relation between psychological well-being and discrimination bothered (i.e., treated as a timevarying covariate) was assessed using a multivariate LCM (see Figure 2 for a pictorial display of Model 2).

Results for Model 1, $\chi^{2}(4)=11.28, \quad p<.05$, $\mathrm{CFI}=.97, \quad \mathrm{RMSEA}=.06$, revealed discrimination significantly predicted the intercept factor for psychological well-being, meaning that on average, individuals with higher reported frequency levels of racial discrimination at Time 1 had lower initial levels of psychological well-being at Time 1 $(b=-.06, p<.01)$. Frequency of discrimination at Time 1 was not found to predict changes in the rate of psychological well-being (i.e., the slope factor for psychological well-being) over time $(b=.01$, $p>.05 ;$ see Table 3). Model $2, \chi^{2}(10)=24.13$, $p<.05$, CFI $=.97$, RMSEA $=.05$, did not reveal any statistically significant results using an alpha level of .05. Findings for Models 1 and 2, including regression coefficients, standard errors, and resid-

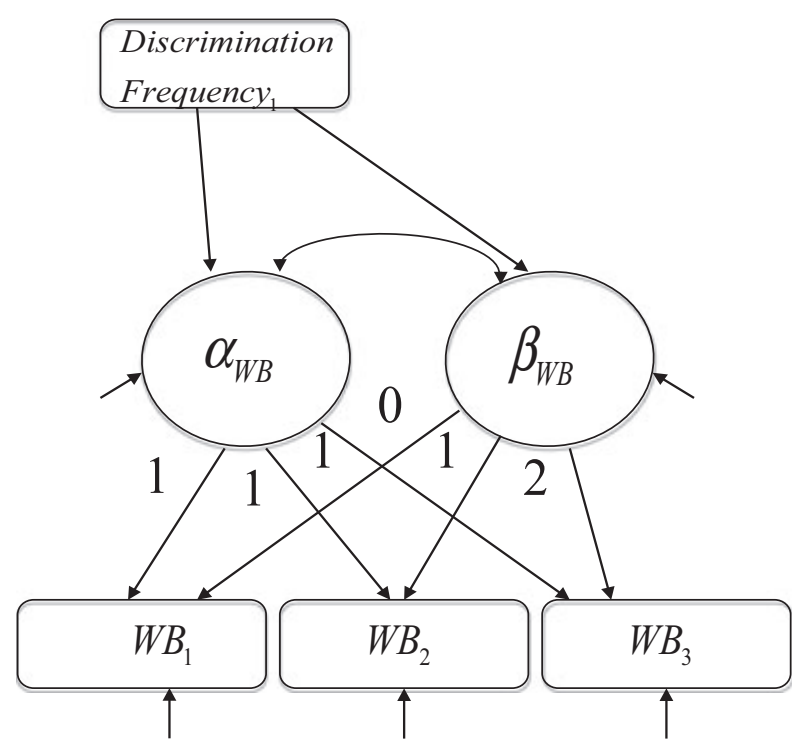

Figure 1. Slope and intercept factor of psychological well-being (WB) regressed on frequency of discrimination at Time 1. 


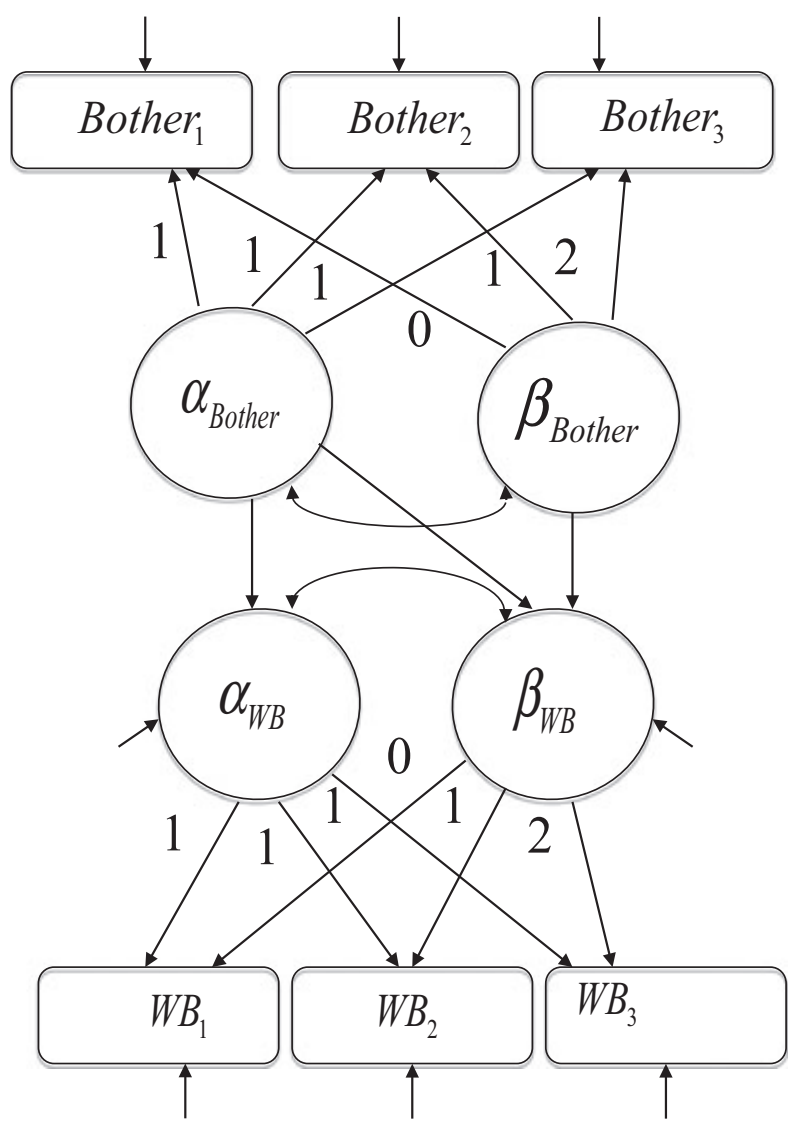

Figure 2. Multivariate LCM: Slope and intercept factor of psychological well-being (WB) regressed on discrimination (bother). ual variances for the slope and intercept factor for psychological well-being appear in Table 3.

\section{Racial Identity Moderating the Relation Between Racial Discrimination Bothered and Frequency of Racial Discrimination on Psychological Well-Being}

A series of models with latent variable interactions were utilized to assess whether the dimensions of racial identity moderated the relation between discrimination bothered and psychological well-being, and the same models were used for frequency of discrimination and psychological wellbeing over time. The multiple-indicator LCMs and parallel process multiple-indicator LCMs for minority ideology did not converge and results were inapplicable. Also, the variance of the slope factor for the multiple-indicator LCMs used to assess private regard, nationalist ideology, assimilationist ideology, and humanist ideology was not statistically significant using an alpha level of .05. In other words, there was not a significant amount of individual variability in the rate of change for these particular racial identity dimensions, whereas the variance of the intercept factor was found to be statistically significant. Due to the nonsignificant slope variances, Models 3, 4, 5, and 6 were parallel process multiple-indicator LCMs used to assess whether initial levels (i.e., intercept factor) of these racial identity dimensions (i.e., private regard,

Table 3

Maximum Likelihood Parameter Estimates and Standard Errors of LCM Models 1 and 2

\begin{tabular}{|c|c|c|c|}
\hline Model & Parameter & $\begin{array}{c}\text { Regression } \\
\text { coefficient }\end{array}$ & $\begin{array}{c}\text { Standard } \\
\text { error }\end{array}$ \\
\hline $\begin{array}{l}\text { Model 1: Slope and intercept } \\
\text { factor for WB regressed on DF at Time } 1\end{array}$ & $\begin{array}{l}\text { WB intercept factor regressed on DF } \\
\text { WB slope factor regressed on DF } \\
\text { Residual variance of WB intercept } \\
\text { Residual variance of WB slope }\end{array}$ & $\begin{array}{l}-.06^{* *} \\
.01 \\
.18^{* *} \\
.03^{* *}\end{array}$ & $\begin{array}{l}.02 \\
.02 \\
.02 \\
.01\end{array}$ \\
\hline $\begin{array}{l}\text { Model fit: } \chi^{2}(4)=11.28 \\
p<.05 ; \mathrm{CFI}=.97, \mathrm{RMSEA}=.06\end{array}$ & & & \\
\hline $\begin{array}{l}\text { Model 2: Multivariate LCM of intercept } \\
\text { and slope factor for WB regressed on DB }\end{array}$ & $\begin{array}{l}\text { WB intercept factor regressed on DB } \\
\text { WB slope factor regressed on DB } \\
\text { Residual variance of WB intercept } \\
\text { Residual variance of WB slope }\end{array}$ & $\begin{array}{l}-.06^{\dagger} \\
-.00 \\
-.09^{\dagger} \\
.18^{* *}\end{array}$ & $\begin{array}{l}.03 \\
.02 \\
.06 \\
.02\end{array}$ \\
\hline
\end{tabular}

Model fit: $\chi^{2}(10)=24.13$,

$p<.05 ; \mathrm{CFI}=.97, \mathrm{RMSEA}=.05$

Note. $\mathrm{LCM}=$ latent curve model; $\mathrm{WB}=$ psychological well-being; $\mathrm{DF}=$ discrimination frequency; $\mathrm{DB}=$ discrimination bothered; $\mathrm{CFI}=$ comparative fit index; RMSEA = root mean square error of approximation.

${ }^{\dagger} p<.10 .{ }^{* *} p<.01$. 
nationalist ideology, assimilationist ideology, and humanist ideology) moderated the relation between the rate of change in psychological well-being (i.e., slope factor) and initial levels for frequency of discrimination at Time 1. Similarly, Models 7 through 10 were parallel process multiple-indicator LCMs used to assess whether initial levels (i.e., intercept factors) of the racial identity dimensions (i.e., private regard, nationalist ideology, assimilationist ideology, and humanist ideology) moderated the relation between the rate of change in psychological well-being (i.e., slope factor) and initial levels of discrimination bothered (i.e., intercept factor). Frequency of discrimination at Time 1 was mean-centered prior to performing the final analyses for Models 3 through 10. Furthermore, the models (Models 5 and 9) used to assess the latent interaction between assimilationist ideology and perceived discrimination (i.e., frequency of discrimination at Time 1 or discrimination bothered) failed to converge. See Figures 3 and 4 for a pictorial representation of Models 3 through 10.

The multiple-indicator LCMs for racial centrality and public regard showed significant variability both in the intercept and slope factor. For Models 11 and 12, we examined parallel process multipleindicator LCMs with latent variable interactions to determine whether initial levels of racial centrality or public regard (i.e., intercept factor) moderated the relation between the rate of change in psychological well-being (i.e., slope factor) and the observed frequency of discrimination at Time 1. In Models 13 and 14, a similar latent variable interaction was constructed to assess whether initial levels of racial centrality or public regard (i.e., intercept factor) moderated the relation between and initial levels of discrimination bothered (i.e., intercept factor) and the rate of change in psychological well-being. Parallel process multiple-indicator LCMs were also tested to determine whether the rate of change (i.e., slope factor) in racial centrality and public regard moderated the relation between the initial levels of racial discrimination (i.e., discrimination bothered or frequency of discrimination) and the rate of change in psychological wellbeing over time. None of the results indicated that a significant interaction effect exists between the slope factor for racial centrality and public regard and initial levels of racial discrimination (i.e., discrimination bothered or frequency of discrimination at Time 1). Frequency of discrimination at Time 1 was mean-centered prior to performing the final analyses for Models 11 through 14. See Figures 3 and 4 for a pictorial representation of Models 11 through 14 .

Overall, results from the final analyses suggested that there was not a statistically significant latent

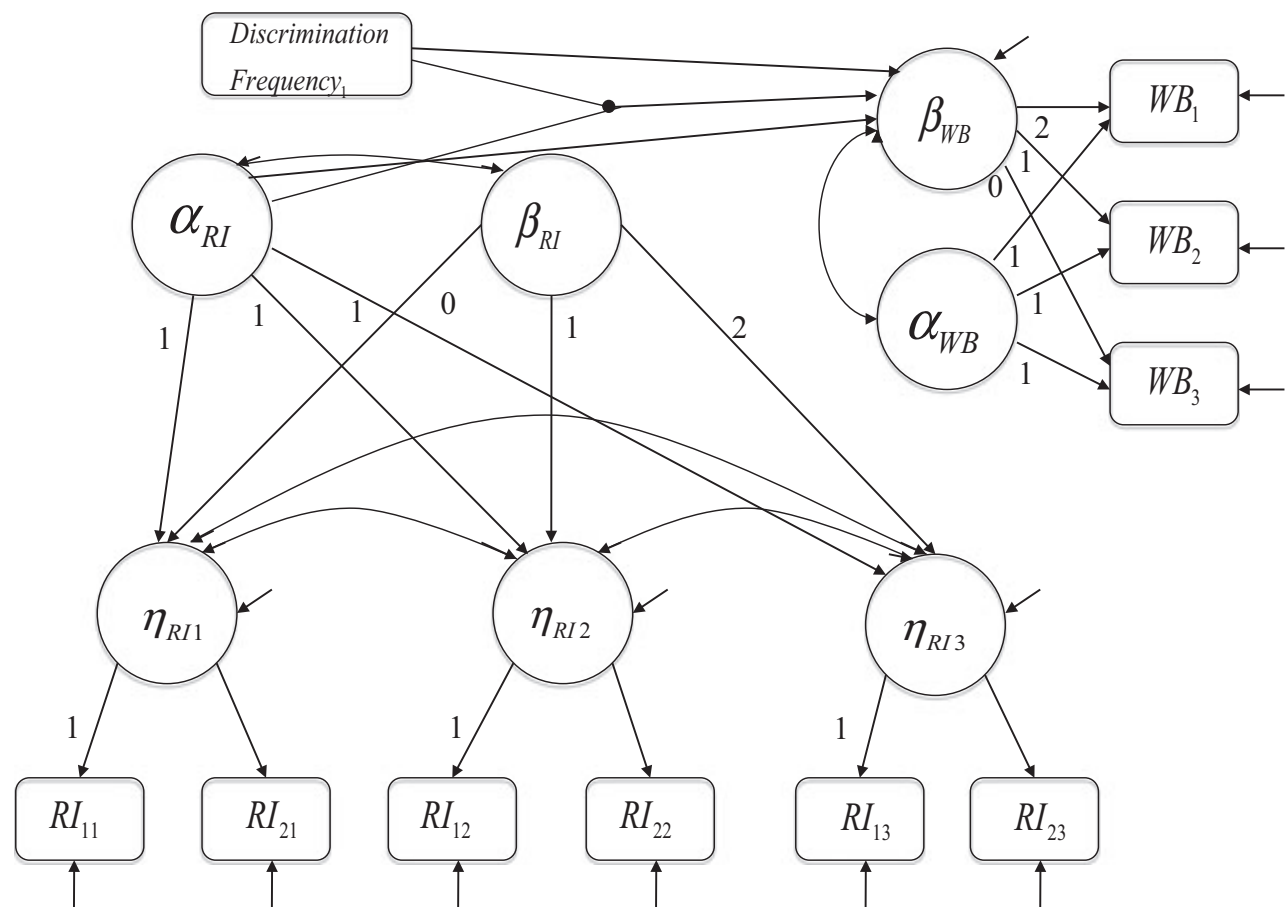

Figure 3. Parallel process multiple-indicator latent curve model with latent intercept for racial identity (RI) moderating the effect of frequency level of discrimination at Time 1 on psychological well-being (WB). 


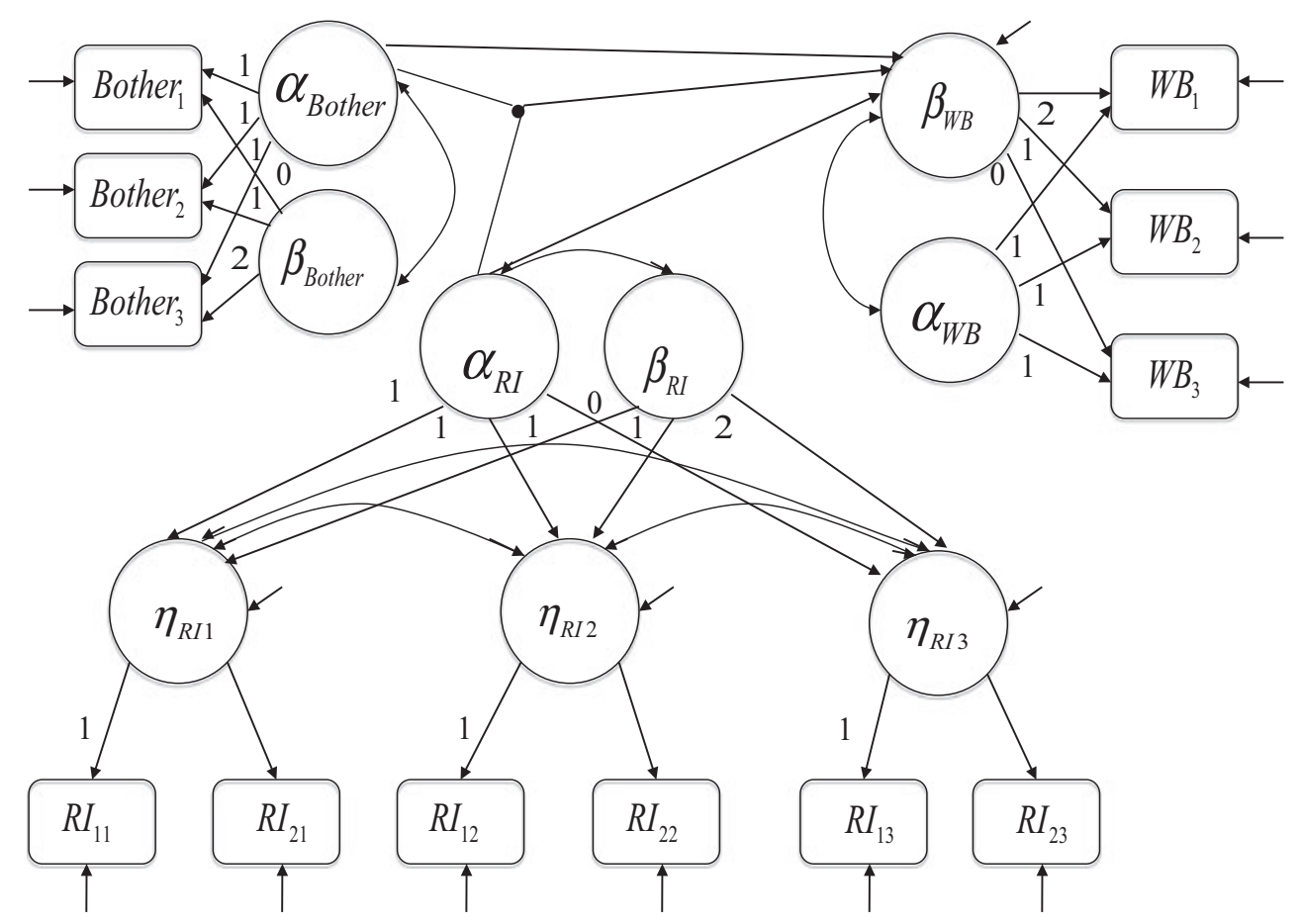

Figure 4. Parallel process multiple-indicator latent curve model with latent intercept for racial identity (RI) moderating the effect of latent intercept for discrimination bothered on psychological well-being (WB).

interaction effect (using an alpha level of .05) between initial levels of private regard, nationalist ideology, assimilationist ideology, and humanist ideology and discrimination (i.e., frequency of discrimination at Time 1 or discrimination bothered). Thus initial assessments of these racial identity constructs (i.e., private regard, nationalist ideology, assimilationist ideology, and humanist ideology) did not moderate the relation between the two measures of discrimination (i.e., frequency of discrimination or discrimination bothered) and the rate of change in psychological well-being over time. Likewise (using an alpha level of .05), none of the models used to examine whether racial centrality or public regard moderated the relation between discrimination (i.e., frequency of discrimination at Time 1 or discrimination bothered) and psychological well-being revealed that a significant latent interaction existed between initial assessments of racial centrality or public regard and assessments of perceived discrimination (i.e., intercept factor for discrimination bothered or discrimination frequency score at Time 1). Taken together, results from Models 3 through 14 indicate that adolescents' racial identity did not moderate the relation between racial discrimination (i.e., intercept factor for discrimination bothered or discrimination frequency score at Time 1) and the rate of change in psychological well-being (i.e., slope factor) over time. Results for Models 3 through 14, including regression coefficients, standard errors, and residual variances for the slope and intercept factor for psychological well-being, appear in Table 4.

\section{Discussion}

Few studies have examined the relation between perceptions of racial discrimination and adolescent developmental outcomes over time. In the present study, we used latent growth curve modeling to examine the prospective relation between perceptions of racial discrimination and psychological well-being. This approach allowed us to assess initial levels of perceived discrimination and wellbeing, as well as changes in well-being over an extended period of time. We found a contemporaneous association between perceived discrimination and well-being, but perceptions of discrimination were unrelated to changes in well-being. Our second objective was to examine whether racial identity moderates the relation between perceptions of racial discrimination and changes in psychological well-being. We found that racial identity did not moderate the relation between racial discrimination and changes in well-being. These data 
Table 4

Maximum Likelihood Parameter Estimates and Standard Errors of LCM Models 3 Through 14

Maximum Likelihood Paraneter Estimates and Standard Errors of LCM Models 3 Through 14

\section{Model}

Model 3: Parallel process multiple-indicator LCM with latent interaction between intercept factor for PrR and DF at Time 1

Model 4: Parallel process multiple-indicator LCM with latent interaction between intercept factor for $\mathrm{N}$ and $\mathrm{DF}$ at Time 1

Model 5: Parallel process multiple-indicator LCM with latent interaction between intercept factor for A and DF at Time 1

Model 6: Parallel process multiple-indicator LCM with latent interaction between intercept factor for $\mathrm{H}$ and $\mathrm{DF}$ at Time 1

Model 7: Parallel process multiple-indicator LCM with latent interaction between intercept factor for PrR and intercept factor for DB

Model 8: Parallel process multiple-indicator LCM with latent interaction between intercept factor for $\mathrm{N}$ and intercept factor for $\mathrm{DB}$

Model 9: Parallel process multiple-indicator LCM with latent interaction between intercept factor for $\mathrm{A}$ and intercept factor for DB

Model 10: Parallel process multiple-indicator LCM with latent interaction between intercept factor for $\mathrm{H}$ and intercept factor for $\mathrm{DB}$

Model 11: Parallel process multiple-indicator LCM with latent interaction between intercept factor for RC and DF at Time 1
WB intercept factor regressed on DF WB slope factor regressed on DF WB slope factor regressed on PrR intercept Interaction effect

Residual variance of WB intercept factor Residual variance of WB slope factor WB intercept factor regressed on DF WB slope factor regressed on DF WB slope factor regressed on $\mathrm{N}$ intercept Interaction effect

Residual variance of WB intercept factor Residual variance of WB slope factor WB intercept factor regressed on DF WB slope factor regressed on DF WB slope factor regressed on A intercept Interaction effect

Residual variance of WB intercept factor Residual variance of WB slope factor WB intercept factor regressed on DF WB slope factor regressed on DF WB slope factor regressed on $\mathrm{H}$ intercept Interaction effect

Residual variance of WB intercept factor Residual variance of WB slope factor WB intercept factor regressed on DB intercept WB slope factor regressed on DB intercept WB slope factor regressed on PrR intercept Interaction effect

Residual variance of WB intercept factor Residual variance of WB slope factor WB intercept factor regressed on DB intercept WB slope factor regressed on DB intercept WB slope factor regressed on $\mathrm{N}$ intercept Interaction effect

Residual variance of WB intercept factor Residual variance of WB slope factor WB intercept factor regressed on DB intercept WB slope factor regressed on DB intercept WB slope factor regressed on A intercept Interaction effect

Residual variance of WB intercept factor Residual variance of WB slope factor WB intercept factor regressed on DB intercept WB slope factor regressed on DB intercept WB slope factor regressed on $\mathrm{H}$ intercept Interaction effect

Residual variance of WB intercept factor Residual variance of WB slope factor WB intercept factor regressed on DF WB slope factor regressed on DF WB slope factor regressed on RC intercept Interaction effect
Regression coefficient

Standard error

$-.06^{* *}$

.01

$-.07$

$.07^{\dagger}$

$.19^{* *}$

$.05^{* *}$

$-.06^{* *}$

.01

$-.02$

.00

$.18^{* *}$

$.05^{* *}$$$
\text { - }
$$$$
-
$$$$
-
$$

$$
-
$$$$
-
$$$$
-.06^{* *}
$$$$
.01
$$$$
-.05
$$$$
.00
$$$$
.18^{* *}
$$$$
.05^{* *}
$$$$
-.07^{*}
$$$$
-.01
$$$$
-.02
$$$$
-.01
$$$$
.19^{* *}
$$$$
.05^{* *}
$$$$
-.06^{* *}
$$$$
-.02
$$$$
.05
$$$$
-.04
$$$$
.19^{* *}
$$$$
.05^{* *}
$$

$$
-
$$$$
-
$$$$
-
$$$$
\text { - }
$$$$
-
$$$$
-.06^{\dagger}
$$$$
.00
$$$$
-.06
$$$$
.00
$$$$
.19^{* *}
$$$$
.04^{* *}
$$$$
-.06^{* *}
$$$$
.01
$$$$
.01
$$

.00
.02

.05

.03

.03

.02

.02

.02

.02

.01

.03

.02

-

$-$

$-$

-

-

-

.02

.02

.04

.04

.03

.02

.03

.02

.13

.07

.03

.02

.03

.03

.06

.03

.03
.03

.02

-

$-$

-

-

-

-

.03

.02

.11

.06

.03

.02

.02

.02

.03

.03 
Table 4

Continued

\begin{tabular}{|c|c|c|c|}
\hline Model & Parameter & $\begin{array}{c}\text { Regression } \\
\text { coefficient }\end{array}$ & $\begin{array}{c}\text { Standard } \\
\text { error }\end{array}$ \\
\hline \multirow{8}{*}{$\begin{array}{l}\text { Model 12: Parallel process multiple-indicator } \\
\text { LCM with latent interaction between intercept } \\
\text { factor for PuR and DF at Time } 1\end{array}$} & Residual variance of WB intercept factor & $.18^{* *}$ & .03 \\
\hline & Residual variance of WB slope factor & $.05^{* *}$ & .02 \\
\hline & WB intercept factor regressed on DB intercept & $-.06^{* *}$ & .02 \\
\hline & WB slope factor regressed on DB intercept & .01 & .02 \\
\hline & WB slope factor regressed on PuR intercept & .01 & .02 \\
\hline & Interaction effect & .00 & .02 \\
\hline & Residual variance of WB intercept factor & $.18^{* *}$ & .03 \\
\hline & Residual variance of WB slope factor & $.05^{* *}$ & .02 \\
\hline \multirow{3}{*}{$\begin{array}{l}\text { Model 13: Parallel process multiple-indicator } \\
\text { LCM with latent interaction between intercept } \\
\text { factor for RC and intercept factor for DB }\end{array}$} & WB intercept factor regressed on DB intercept & $-.06^{\dagger}$ & .03 \\
\hline & WB slope factor regressed on DB intercept & -.00 & .02 \\
\hline & WB slope factor regressed on RC intercept & .09 & .08 \\
\hline \multirow{9}{*}{$\begin{array}{l}\text { Model 14: Parallel process multiple-indicator } \\
\text { LCM with latent interaction between intercept } \\
\text { factor for PuR and DF at Time } 1\end{array}$} & Interaction effect & -.04 & .05 \\
\hline & Residual variance of WB intercept factor & $.19^{* *}$ & .03 \\
\hline & Residual variance of WB slope factor & $.05^{* *}$ & .02 \\
\hline & WB intercept factor regressed on DF & -.04 & .03 \\
\hline & WB slope factor regressed on DF & -.02 & .03 \\
\hline & WB slope factor regressed on PuR intercept & -.06 & .05 \\
\hline & Interaction effect & $.05^{\dagger}$ & .03 \\
\hline & Residual variance of WB intercept factor & $.19^{* *}$ & .03 \\
\hline & Residual variance of WB slope factor & $.05^{* *}$ & .02 \\
\hline
\end{tabular}

Note. $\mathrm{LCM}=$ latent curve model; $\mathrm{DF}=$ discrimination frequency; $\mathrm{DB}=$ discrimination bothered; $\mathrm{WB}=$ well-being; $\mathrm{RC}=\mathrm{racial}$ centrality; $\mathrm{PrR}=$ private regard; $\mathrm{PuR}=$ public regard; $\mathrm{N}=$ nationalist ideology; $\mathrm{A}=$ assimilation ideology; $\mathrm{H}=$ humanism ideology. ${ }^{\dagger} p<.10{ }^{*} p<.05 .{ }^{* *} p<.01$.

remind us of the negative association between racial discrimination and positive psychological adjustment, while they also raise questions about the relation between racial discrimination and well-being over time.

\section{Perceptions of Racial Discrimination and Psychological Well-Being}

Consistent with several studies to document the negative psychological correlates of racial discrimination experiences in African American adolescents (Brody et al., 2006; Seaton et al., 2008; Sellers et al., 2006), we found that both initial levels of perceived racial discrimination bother as well as the frequency of racial discrimination experiences were negatively related to initial levels of well-being. Although prior studies have focused primarily on the frequency of racial discrimination experiences, the present results suggest that it is also important to consider the psychological impact of racial discrimination as it relates to well-being and other developmental outcomes. In fact, the psychological experience (i.e., bother) of racial discrimination may account, in part, for an increasing number of studies to document relations between racial dis- crimination experiences and psychological adjustment outcomes in African American adolescents (Prelow et al., 2004; Simons et al., 2002; Wong et al., 2003). Higher levels of bother in the aftermath of racial discrimination experiences, in the absence of appropriate protective factors, might be more likely, for instance, to lead to conduct problems and depressive symptoms (Brody et al., 2006), decreased psychological well-being, and other important developmental outcomes.

We did not find that initial levels of either index of perceived discrimination were related to decreases in well-being, suggesting that in the present sample, neither the psychological experience of discrimination (as measured by bother) nor the frequency of racial discrimination leads to changes in well-being. One possible explanation of the null findings concerns our measurement of racial discrimination in the present study. Whereas some racial discrimination scholars have adopted a major life events approach (i.e., major events that can change a person's entire life course) and employed more domain-specific approaches in the measurement of discrimination experiences such as school or peer discrimination (see Chavous et al., 2008), the measure used in the present study captured chronic 
daily hassles (i.e., minor and subtle behaviors that occur more frequently) that take place across multiple domains. These subtle differences may be important to consider in assessing the overall impact of perceived discrimination experiences on adolescent development over time. A second potential explanation for the failure to find a prospective relation is that adolescent well-being may influence perceptions of discrimination experiences and not vice versa. However, neither prior longitudinal studies of discrimination and developmental outcomes (e.g., Gee \& Walsemann, 2009) nor the present data support this contention (e.g., the wellbeing intercept was not related to the slope for discrimination bother). A third possibility is that the true relation between perceived discrimination experiences and well-being necessitates the further consideration of important mediating and moderating variables or influences. It may be, for instance, that levels of perceived stress account for the relation between perceptions of discrimination experiences and well-being over time. Few studies have measured general measures of stress (i.e., stress above and beyond racial discrimination experiences) when examining the relation between perceptions of discrimination experiences and psychological adjustment outcomes, making it unclear whether the relation between discrimination and these variables is also accounted for by overall levels of stress or other third variables.

\section{Racial Identity as a Moderator}

Prior studies of the prospective impact of racial discrimination on psychological adjustment have investigated nonrace-related protective factors such as parenting, peer relations, and academic performance (e.g., Brody et al., 2006). Although these factors are important to consider, the PVEST developmental framework (Spencer et al., 2006) suggests that identity processes such as cultural and ethnic identity (in conjunction with other domains of identity) are especially important to consider in developmental outcomes for racially and ethnically diverse youth. Surprisingly, we found that racial identity did not moderate the relation between either dimension of racial discrimination and changes in psychological well-being. In contrast to prior studies that have reported a buffering effect of various dimensions of racial identity (e.g., Sellers et al., 2006), none of the dimensions of racial identity measured in the present study buffered the psychological experience or frequency of racial discrimination. These data raise questions about the long-term impact of racial discrimination on psychological well-being. We do not know, for example, whether racial identity truly fails to act as a protective factor in the relation between discrimination and well-being over time, or whether alternative explanations such as methodological considerations may account for the unexpected results.

Several possibilities are worthy of further investigation. First, it may be that the moderating effects of racial identity occur over a shorter time frame than our analyses can detect. For example, it may be that racial identity moderates the psychological effects of discrimination in the short term but not in the long term. With measurements taken approximately 1 year apart, it would be difficult to capture moderating effects of identity that might take place at the level of the discriminatory event or more proximally. Second, the moderating effect of racial identity may be masked by considering each dimension of racial identity independently. Given that Sellers' MMRI suggests that individuals possess various dimensions of racial identity simultaneously (as opposed to being characterized solely by one dimension), it may prove useful in future studies to adopt person-centered approaches to evaluate the moderating capacity of racial identity. It may be the case that particular profiles or patterns of racial identity capture the moderating impact of racial discrimination over time in ways that are masked in conducting a more one-dimensional analysis. Third, the absence of a moderating effect for racial identity in the prospective relation between racial identity and well-being does not rule out the possibility that racial identity may buffer the psychological effects of discrimination and the frequency of discrimination with respect to other developmental outcomes. Further investigations of other adaptive competencies will be necessary before any demonstrative conclusion can be made with respect to the moderating capacity of racial identity over time. Finally, the racial identity measure used in the study consisted of subscales with only two items. The fact that there were only two items to represent racial identity dimensions that typically consist of seven or more items (in the full scale; Sellers, Rowley, Chavous, Shelton, \& Smith, 1997) may have contributed to the lack of significant moderation. In sum, several alternatives will need to be evaluated before dismissing the potential protective nature of racial identity in the context of racial discrimination suggested by extant theoretical frameworks (e.g., Garcia Coll et al., 1996; Spencer et al., 2003) and prior cross-sectional studies. 


\section{Future Directions}

The findings from the present study raise critical questions that have the potential to shape future research and advance our knowledge and understanding of African American youth's experiences with racial discrimination and how these experiences shape youth developmental competencies over time. First, future prospective investigations of the impact of racial discrimination experiences should consider multiple dimensions and domains of racial discrimination experiences as they may have differing implications for well-being and other indices of psychological adjustment over time. As we have noted previously, this study focused on day-to-day racial hassles, as opposed to racial life events or domain-specific instances of racial discrimination. It may be that racist life events are more influential than day-to-day hassles, or perhaps it is peer discrimination that is particularly virulent given the developmental salience of peers during adolescence. Second, although there is value in considering the subjective experience of bother in perceptions of racial discrimination, it will be important to further investigate the relation between perceptions of racial discrimination and well-being in a sample with greater variability around the occurrence of racial discrimination experiences. Third, we suggest that future studies be extended to include a broader range of adolescent developmental outcomes, inclusive of but not limited to well-being. Such investigations would add to the current study and other initial work to examine the prospective impact of racial discrimination experiences on psychological adjustment outcomes (e.g., Brody et al., 2006). Finally, our analytic strategy focused on the moderating effects of one dimension of racial identity (e.g., racial centrality, humanist ideology, etc.) at a time. Adolescents rarely endorse only one dimension of racial identity (e.g., I may believe that race is important to who I am, but also see commonalities between African Americans and all humans; Sellers et al., 1998), and so a profile- or person-centered approach (e.g., Banks \& Kohn-Wood, 2007; Seaton, 2009; Seaton et al., 2006; Yip, Seaton, \& Sellers, 2006) may be more fitting in future work.

\section{Conclusion}

The current study used three waves of data to build upon a small, but increasing number of studies to examine the role of racial identity in the context of racial discrimination experiences and African American adolescent developmental outcomes. The analysis used in this study provides evidence that for some African American adolescents, both psychological responses to discrimination experiences and the frequency of racial discrimination are associated with psychological well-being. Future work will need to explore the time frame under which discrimination influences well-being, the multidimensional conceptualization of racial identity, and additional adolescent developmental outcomes. We hope that future research will build upon our current findings to further illuminate the complex processes by which African American racial identity can serve as a protective factor in the face of ongoing racial adversity.

\section{References}

Banks, K. H., \& Kohn-Wood, L. P. (2007). The influence of racial identity profiles on the relationship between racial discrimination and depressive symptoms. Journal of Black Psychology, 33, 331-354.

Barksdale, D. J., Farrug, E. R., \& Harkness, K. (2009). Racial discrimination and blood pressure: Perceptions, emotions and behaviors of Black American adults. Issues in Mental Health Nursing, 30, 104-111.

Bolger, N., \& Zuckerman, A. (1995). A framework for studying personality in the stress process. Journal of Personality and Social Psychology, 69, 890-902.

Bollen, K. A. (1989). Structural equations with latent variables. New York: Wiley.

Bollen, K. A., \& Curran, P. J. (2006). Latent curve models: A structural equation perspective. New York: Wiley.

Brody, G. H., Chen, Y., Murry, V. M., Ge, X., Simons, R. L., Gibbons, F. X., et al. (2006). Perceived discrimination and the adjustment of African American youths: A five-year longitudinal analysis with contextual moderation effects. Child Development, 77, 1170-1189.

Burchinal, M. R., Roberts, J. E., Zeisel, S. A., \& Rowley, S. J. (2008). Social risk and protective factors for African American children's academic achievement and adjustment during the transition to middle school. Developmental Psychology, 44, 286-292.

Chavous, T. M., Rivas-Drake, D., Smalls, C., Griffin, T., \& Cogburn, C. (2008). Gender matters, too: The influences of school racial discrimination and racial identity on academic engagement outcomes among African American adolescents. Developmental Psychology, 44, 637-654.

Eccles, J. S., Wong, C. A., \& Peck, S. C. (2006). Ethnicity as a social context for the development of African American adolescents. Journal of School Psychology, 44, 407-426.

Erikson, E. (1968). Identity, youth and crisis. New York: Norton. 
Fisher, C. B., Wallace, S. A., \& Fenton, R. E. (2000). Discrimination distress during adolescence. Journal of Youth and Adolescence, 29, 679-695.

French, S. E., Seidman, E., Allen, L., \& Aber, J. L. (2006). The development of ethnic identity during adolescence. Developmental Psychology, 42, 1-10.

Garcia Coll, C., Lamberty, G., Jenkins, R., McAdoo, H. P., Crnic, K., Wasik, B. H., et al. (1996). An integrative model for the study of developmental competencies in minority children. Child Development, 67, 1891-1914.

Gaylord-Harden, N. K., \& Cunningham, J. A. (2009). The impact of racial discrimination and coping strategies on internalizing symptoms in African American youth. Journal of Youth and Adolescence, 38, 532-543.

Gee, G., \& Walsemann, K. (2009). Does health predict the reporting of racial discrimination or do reports of discrimination predict health? Findings from the National Longitudinal Study of Youth. Social Science and Medicince, 68, 1676-1684.

Gibbons, F. X., Gerrard, M., Cleveland, M. J., Wills, T. A., \& Brody, G. (2004). Perceived discrimination and substance use in African American parents and their children: A panel study. Journal of Personality and Social Psychology, 86, 517-529.

Gibbons, F. X., Yeh, H. C., Gerrard, M., Cleveland, M. J., Cutrona, C., Simons, R. L., et al. (2007). Early experience with racial discrimination and conduct disorder as predictors of subsequent drug use: A critical period hypothesis. Drug and Alcohol Dependence, 88, 27-37.

Greene, M. L., Way, N., \& Pahl, K. (2006). Trajectories of perceived adult and peer discrimination among Black, Latino and Asian American adolescents: Patterns and psychological correlates. Developmental Psychology, 42, 218-238.

Guthrie, B. J., Young, A. M., Williams, D. R., Boyd, C. J., \& Kintner, E. K. (2002). African American girls' smoking habits and day-to-day experiences with racial discrimination. Nursing Research, 51, 183-190.

Hancock, G. R., \& Kuo, W. (2001). An illustration of second-order latent growth models. Structural Equation Modeling, 8, 470-489.

Harrell, S. P. (1994). The racism and life experience scales. Unpublished manuscript.

MacCallum, R. C., Zhang, S., Preacher, K. J., \& Rucker, D. D. (2002). On the practice of dichotomization of quantitative variables. Psychological Methods, 7, 19-40.

Meredith, W. (1993). Measurement invariance, factor analysis and factorial invariance. Psychometrika, 58, 525-543.

Muthén, L. K., \& Muthén, B. O. (1998-2007). Mplus user's guide (1998-2007). Los Angeles: Authors.

Neblett, E. W., White, R. L., Ford, K. R., Philip, C. L., Nguyên, H. X., \& Sellers, R. M. (2008). Patterns of racial socialization and psychological adjustment: Can parental communications about race reduce the impact of racial discrimination? Journal of Research on Adolescence, $18,477-515$.
Ong, A. D., Fuller-Rowell, T., \& Burrow, A. L. (2009). Racial discrimination and the stress process. Journal of Personality and Social Psychology, 96, 1259-1271.

Pahl, K., \& Way, N. (2006). Longitudinal trajectories of ethnic identity among urban Black and Latino adolescents. Child Development, 77, 1403-1415.

Phinney, J. S., Madden, T., \& Santos, L. J. (1998). Psychological variables as predictors of perceived ethnic discrimination among minority and immigrant adolescents. Journal of Applied Social Psychology, 28, 937-953.

Powell, C. L., \& Arriola, K. R. J. (2003). Relation between psychosocial factors and academic achievement among African American students. Journal of Educational Research, 96, 175-181.

Prelow, H. M., Danoff-Burg, S., Swenson, R. R., \& Pulgiano, D. (2004). The impact of ecological risk and perceived discrimination on the psychological adjustment of African American and European American Youth. Journal of Community Psychology, 32, 375-389.

Ryff, C. (1989). Happiness is everything, or is it? Explorations on the meaning of psychological well-being. Journal of Personality and Social Psychology, 57, 10691081.

Ryff, C., \& Keyes, C. L. (1995). The structure of psychological well-being revisited. Journal of Personality and Social Psychology, 69, 719-727.

Sayer, A. G., \& Cumsille, P. E. (2001). Second-order latent growth models. In L. M. Collins \& A. G. Sayer (Eds.), New methods for the analysis of change (pp. 179-200). Washington, DC: American Psychological Association.

Schumacker, R., \& Marcoulides, G. (Eds.). (1998). Interaction and nonlinear effects in structural equation modeling. Mahwah, NJ: Erlbaum.

Scottham, K. M., Sellers, R. M., \& Nguyên, H. X. (2008). A measure of racial identity in African American adolescents: The development of the Multidimensional Inventory of Black Identity-Teen. Cultural Diversity and Ethnic Minority Psychology, 14, 297-306.

Seaton, E. K. (2009). Perceived racial discrimination and racial identity profiles among African American adolescents. Cultural Diversity and Ethnic Minority Psychology, 15, 137-144.

Seaton, E. K., Caldwell, C. H., Sellers, R. M., \& Jackson, J. S. (2008). The prevalence of perceived discrimination among African American and Caribbean Black youth. Developmental Psychology, 44, 1288-1297.

Seaton, E. K., Scottham, K. M., \& Sellers, R. M. (2006). The status model of ethnic identity development in African American adolescents: Evidence of structure, trajectories and well-being. Child Development, 77, 14161426.

Seaton, E. K., Yip, T., \& Sellers, R. M. (2009). A longitudinal examination of racial identity and racial discrimination among African American adolescents. Child Development, 80, 406-417.

Sellers, R. M., Linder, N. C., Martin, P. M., \& Lewis, R. L. (2006). Racial identity matters: The relationship between racial discrimination and psychological func- 
tioning in African American adolescents. Journal of Research on Adolescence, 16, 187-216.

Sellers, R. M., Rowley, S. J., Chavous, T. N., Shelton, J. N., \& Smith, M. (1997). Multidimensional Inventory of Black Identity: Preliminary investigation of reliability and construct validity. Journal of Personality and Social Psychology, 73, 805-815.

Sellers, R. M., Smith, M., Shelton, J. N., Rowley, S. J., \& Chavous, T. M. (1998). Multidimensional model of racial identity: A reconceptualization of African American racial identity. Personality and Social Psychology Review, 2, 18-39.

Simons, R. L., Murry, V., McLoyd, V., Lin, K., Cutrona, C., \& Conger, R. D. (2002). Discrimination, crime, ethnic identity, and parenting as correlates of depressive symptoms among African American children: A multilevel analysis. Development and Psychopathology, 14, 371393.

Singer, J. D., \& Willett, J. B. (2003). Applied longitudinal data analysis: Modeling change and next occurrence. New York: Oxford University Press.

Smalls, C., White, R., Chavous, T., \& Sellers, R. (2007). Racial ideological beliefs and racial discrimination experiences as predictors of academic engagement among African American adolescents. Journal of Black Psychology, 33, 299-330.

Spencer, M. B. (2005). Crafting identities and assessing opportunities post-Brown. American Psychologist, 60, 821-830.

Spencer, M. B. (2006). Phenomenology and ecological systems theory: Development of diverse groups. In W. Damon (Series Ed.) \& R. Lerner (Vol. Ed.), Handbook of child psychology: Vol. 1. Theoretical models of human development (6th ed., pp. 829-893). New York: Wiley.
Spencer, M. B., Fegley, S. G., \& Harplani, V. (2003). A theoretical and empirical examination of identity as coping: Linking coping resources to the self processes of African American youth. Applied Developmental Science, 7, 181-188.

Spencer, M. B., Harpalani, V., Cassidy, E., Jacobs, C. Y., Donde, S., Goss, T. N., et al. (2006). Understanding vulnerability and resilience from a normal developmental perspective: Implications for racially and ethnically diverse youth. In D. Cicchetti \& D. J. Cohen (Eds.), Developmental psychopathology, Vol. 1. Theory and method (2nd ed., pp. 627-672). Hoboken, NJ: Wiley.

Swanson, D. P., Spencer, M. B., Harpalani, V., Dupree, D., Noll, E., Ginzburg, S., et al. (2003). Psychosocial development in racially and ethnically diverse youth: Conceptual and methodological challenges in the 21st century. Development and Psychopathology, 15, 711-743.

Terrell, F., Miller, A. R., Foster, K., \& Watkins, C. E. (2006). Racial discrimination-induced anger and alcohol use among Black adolescents. Adolescence, 41, 485492.

Williams, D. R., Neighbors, H. W., \& Jackson, J. S. (2003). Racial/ethnic discrimination and health: Findings from community studies. American Journal of Public Health, 93, 200-208.

Wong, C. A., Eccles, J. S., \& Sameroff, A. (2003). The influence of ethnic discrimination and ethnic identification on African American adolescents' school and socioemotional adjustment. Journal of Personality, 71, 1197-1232.

Yip, T., Seaton, E. K., \& Sellers, R. M. (2006). African American racial identity across the lifespan: Identity status, identity context and depressive symptoms. Child Development, 77, 1503-1516. 